\title{
Study on the Near-Wake Flow behind EBMC Flameholder
}

\author{
Lianjie Yue ${ }^{1}$, Baojie Liu ${ }^{2}$, Maolin Yang ${ }^{2}$ \\ ${ }^{1}$ Laboratory of High Temperature Gas Dynamics \\ Institute of Mechanics, Chinese Academy of Sciences \\ Beijing, China 100080 \\ Tel: 086-010-62613248 \\ E-mail address: yuelianjie@sohu.com \\ ${ }^{2}$ Jet Propulsion Department Of Beijing University of Aeronautics and Astronautics
}

Abstract: The detailed near-wake flow behind the Edge Blowing Mixture Curtain flameholder (EBMC flameholder) and the V-gutter flameholder were investigated by using 2D cross-correlation on-line PIV in a low speed wind tunnel. Experiments were conducted at the main flow velocity of $10 \mathrm{~m} / \mathrm{s}$ and $20 \mathrm{~m} / \mathrm{s}$, the jet velocity of $10 \mathrm{~m} / \mathrm{s}$ and $20 \mathrm{~m} / \mathrm{s}$ respectively. Results show that near-wake flow structure of both flameholders is governed mainly by large-scale vortices in the form of vortex street, and the jet increases the size of the vortices. But symmetrical large-scale vortices appear when the momentum ratio of the jet to the main flow is high, which is disadvantage to combustion. Based on the research on the instantaneous flow, the instantaneous viewpoint of the flame stability mechanism was brought forward. Important effect of alternate formation and shedding of vortices on the flame stability was discussed. All of these offer important theoretic basis for further studying combustion performance of the novel flameholder.

Key words: near-wake flow, flameholder, jet, flame stability mechanism

Nomenclature

$X$ the direction of the main flow

$Y$ the vertical direction

coordinate origin locates at the intersection point of middle line of the flameholder and trailing edge.

$V_{m}$ the main flow velocity

$V_{j}$ the jet velocity

\section{Introduction}

An aircraft jet engine generally employs an afterburner for augmenting engine thrust during take off or acceleration. As an important component of the afterburner, the flameholder has profound influence on the afterburning performance. The conventional method of stabilizing flame is by use of V-gutter flameholder. At present, the development of the jet engine set a higher demand on the flameholder, such as reliable ignition, wider stability limit, higher combustion efficiency, lower pressure loss and ability of working at higher inlet temperature. Conventional bluff body flameholder can't meet the requirements above. So various methods of stabilizing flame were proposed, for instance, evaporating flameholder, jet curtain flameholder ${ }^{[1][2][3]}$ and the dune flameholder ${ }^{[4]}$.

Combustion research group of BUAA reviewed the development history of flameholders, designed a novel flameholder__Edge Blowing Mixture Curtain flameholder (EBMC flameholder) ${ }^{[5]}$, which combines the characteristics of small bluff body and jet curtain flameholder, as shown in Fig.4. 
On non-afterburning case, its pressure loss is lower because of its narrower base width and streamlined head. On case of afterburning, air and fuel are supplied into the flameholder through airblast atomizers, then the mixture ejects from the edge slot, which improves the combustion performance of the afterburner. Its air jet mass is much less than that of the jet curtain flameholder and it can work more stably. Elementary experimental results showed the novel flameholder was hopeful.

In addition to the fuel concentration distribution, the combustion performance depends to a great extent on the flow behind the flameholder which considerable efforts have been made to study ${ }^{[1][6][7]}$. Especially for EBMC flameholder, its flow field is more complicated. There are the interaction between the main flow and the jet, and the entrainment of the recirculation zone to the jet. Sufficient knowledge of the flow structure is crucial in better understanding the combustion phenomena. Before flow analysis mainly focused on characteristics of time-averaged flow due to experiment device limits. But in fact the wake flow behind the flameholder is unsteady turbulence flow, and the combustion process has close relations with vortex. In this paper the detailed near-wake flow behind the EBMC flameholder and the V-gutter flameholder were measured by using 2D cross-correlation on-line PIV.

\section{Experimental Configuration}

\subsection{Low speed wind tunnel}

Experiment was conducted in open-circuit and rear-suction low-speed wind tunnel with a closed test section of $560 \mathrm{~mm}$ wide $\times 800 \mathrm{~mm}$ high $\times 1500 \mathrm{~mm}$ long whose free stream turbulence intensity is less than $0.25 \%$. Fig. 1 shows a side view of the wind tunnel. In order to study the confined flow, the flameholder is installed vertically in a small experimental section of $120 \mathrm{~mm}$ high $\times 200 \mathrm{~mm}$ wide $\times$ $1500 \mathrm{~mm}$ long mounted in center of the test section.

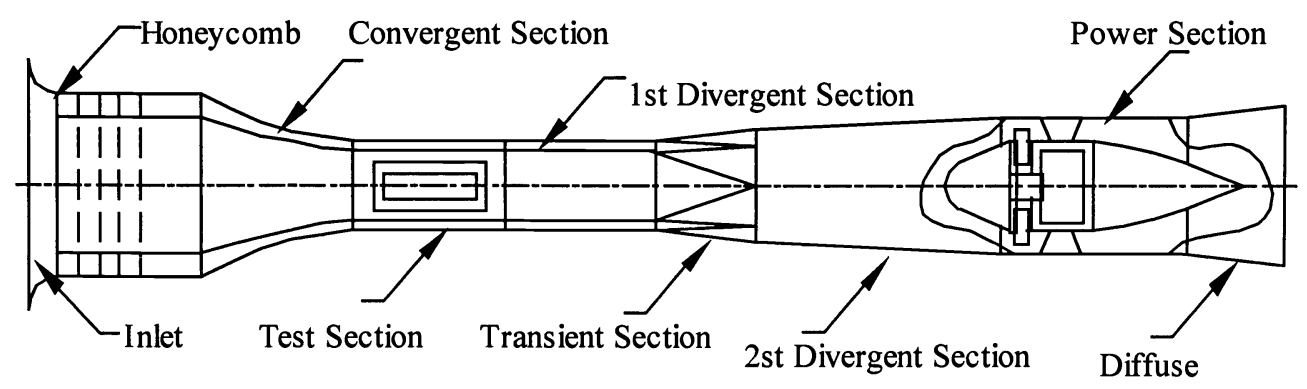

Fig.1 Sketch of Low Speed Wind Tunnel

\subsection{On-line PIV system}

Fig.2 is sketch of the on-line PIV system of TSI used in the experiment, which consists of laser, cross-correlation CCD, synchronizer, and acquisition computer. The laser is an integrated double-pulsed Nd: YAG laser whose repetition rate is $10 \mathrm{~Hz}$ and can provide maximum energy output of $200 \mathrm{~mJ} /$ pulse at the wavelength of $532 \mathrm{~nm}$ (green light) with the pulse duration of $9 \mathrm{~ns}$. The pulse separation could be varied from $200 \mathrm{~ns}$ to $100 \mathrm{~ms}$, which permits the measurements from low speed to high-speed in large facilities. The light sheet enters the test section from the side of window which is made of polymethyl methacrylate, as shown in Fig.3. 
The images were acquired by a RS-170 Auto/cross correlation CCD with the resolution of $640 \times 480$ pixels. The acquisition frame rate is $30 \mathrm{~Hz}$, and the minimum time separation between two frames of an image pair is about $15 \mu \mathrm{s}$.

The seeding particles were supplied to the entrance of the low-speed wind tunnel from a generator. In the generator, the liquid glycerol would be heated into vapor, and then the vapor be cooled to generate the desired mist which was composed of seeding particles with proper aerodynamic diameter of about $1 \mu \mathrm{m}$ and in appropriate thickness.

The normal frequency of PIV is far lower than the typical characteristic frequency of unsteady flow, so PIV can't provide detailed vortex evolution process, which is also a common problem in the application of PIV to the study on unsteady flow.

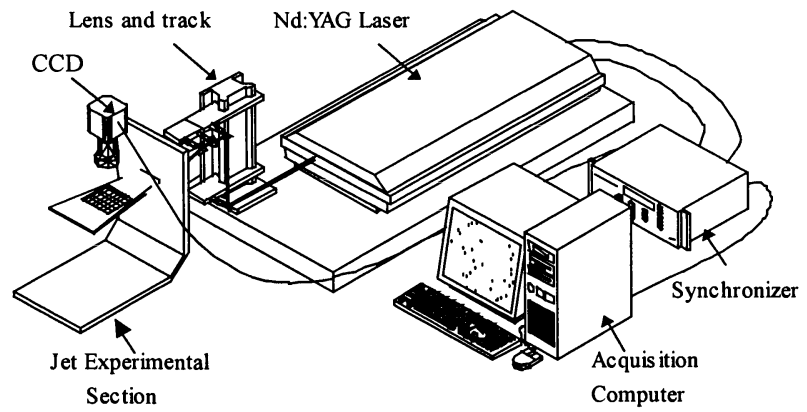

Fig.2 Sketch of On-line PIV System

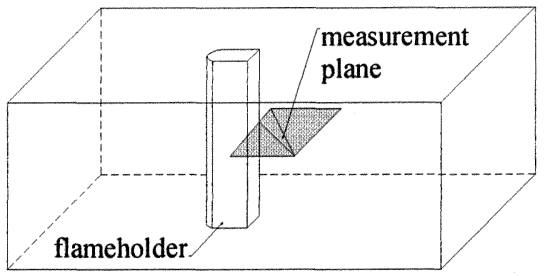

Fig.3 Sketch of Test Section

\section{Experiment Setup}

The diagrams of the flameholders are shown in Fig.4 and Fig.5. The base width of both flameholders is $23 \mathrm{~mm}$ with their geometrical blockage of $11.5 \%$. The flow field of the V-gutter flameholder was measured at $V_{m}=10 \mathrm{~m} / \mathrm{s}$ and the experimental states of EBMC flameholder are shown in Table.1. The corresponding Reynold number of the main flow based on the base width of the flameholder is about $10^{4}$.

In present experiment, the $\mathrm{CCD}$ acquisition region is $57.5 \times 43 \mathrm{~mm}^{2}$ which is not large enough to cover the near wake field, so the flow was measured at two adjacent locations along the main flow direction. At each test location, 6 groups of image were captured and each group of image included 32 frames, thus 96 instantaneous velocity fields were collected. In the analysis of images, the interrogation region is $64 \times 64$ pixels and overlapped by one-half the domain size in order to enhance overall resolution.
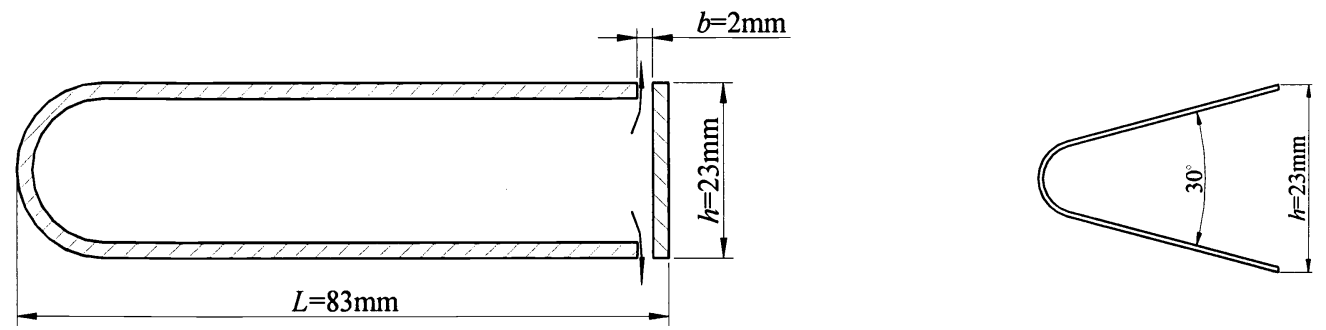

Fig.4 Sketch of EBMC Flameholder

Fig.5 Sketch of the V-gutter Flameholder 
Table.1 Experiment States of EBMC Flameholder

\begin{tabular}{|c|c|c|c|c|}
\hline & state 1 & state 2 & state 3 & state 4 \\
\hline$V_{m}$ & $10 \mathrm{~m} / \mathrm{s}$ & $10 \mathrm{~m} / \mathrm{s}$ & $20 \mathrm{~m} / \mathrm{s}$ & $20 \mathrm{~m} / \mathrm{s}$ \\
\hline$V_{j}$ & $10 \mathrm{~m} / \mathrm{s}$ & $20 \mathrm{~m} / \mathrm{s}$ & $10 \mathrm{~m} / \mathrm{s}$ & $20 \mathrm{~m} / \mathrm{s}$ \\
\hline
\end{tabular}

\section{Experiment Results and Discussion}

In research on the wake flow, interest to vortices is always focused on the concentrated vortex with vortex core that is also the main kind vortex of coherent structures. But the results directly measured by PIV are the instantaneous velocity field, so it is necessary to identify the vortex caused by flow interaction firstly in order to study the vortex structures and their flow mechanism.

With the negative $\lambda 2$-definition deduced by J. Jeong and F. Hussain basing on the physic principle that vortex rotation could cause a low-pressure zone in the vortex core ${ }^{[8]}$, Liu Baojie deduced the vortex identification criteria for 2-dimensonal velocity field using "Eigenvalue Partition Hypnosis" as follows ${ }^{[9]}$,

$$
\left.\begin{array}{l}
u_{1,1}^{2}+u_{2,2}^{2}+2 u_{1,2} u_{2,1}<\varepsilon \\
\text { Pure Vorticity in Vortex Core }
\end{array}\right\}
$$

where $\varepsilon$ is a negative control parameter.

The high-pressure zone caused by flow interaction can be identified by positive $\lambda_{2}$-definition. Similarly, it is as follows for 2-dimensional velocity field.

$$
u_{1,1}^{2}+u_{2,2}^{2}+2 u_{1,2} u_{2,1}>\gamma
$$

where $\gamma$ is a positive control parameter.

In Equations (1) and (2), $u_{l}$ and $u_{2}$ are the velocity components with respect to $\mathrm{x}$ and $\mathrm{y}$ axes, respectively, and $u_{l, 2}$ is the gradient of $u_{l}$ along y-axis, and so on.

In the following figures, (a) are combined diagrams of the instantaneous velocity vectors, the vortex cores (low-pressure zones; dark blue color) and the high-pressure zones (green to red color). They are calculated from Equations (1) and (2), while (b) is the composite picture of streamlines and the vorticity color contour.

\subsection{Analysis on the flow behind the V-gutter flameholder}

\subsubsection{Near-wake flow structure}

As clearly illustrated in Fig.6 and Fig.7, the streamline patterns reveal the complexity of the near-wake flow structure governed mainly by large scale vortices existing in the form of evolution process of alternate formation, development and shedding, which is known as vortex street similar to that past cylinder. The kind of flow is K-H type unsteady, and the streamlines of the shear layer take the form of wave. There is also a recirculation zone with relatively low velocity. Free shear layers originate from separation points that can only locate at the sharp edges of the flameholder, which is different with the flow past the cylinder. Distinct velocity difference exists between two sides of the shear layer, constructing a boundary surface of the main flow and low speed flow in the recirculation zone.

Meanwhile, the vorticity can be only produced from the wall surface of flameholder, and it is transferred through the shear layers into the recirculation zone and concentrates on a certain point. 


\subsubsection{Formation mechanism of vortex street}

In Fig.6 (1), a vivid large-scale vortex has developed adequately in the region of one base width distance behind the flameholder. It is strong enough to dominate the flow field nearby, so that the high-pressure zone is formed in the opposite free shear layer that is then cut off, corresponding to a saddle point drawn in the streamlines. The vorticity can't be transferred downstream and accumulates at the cutting point. Therefore, A new vortex is formed near the trailing edge. It can be sure to develop continually due to good stability of the developed large-scale vortex. The downstream vortex with positive vorticity loses touch with upstream shear layer and sheds.

Because the flow in shear layer entrained by the new vortex has higher momentum along main flow direction, the vortex will move downstream due to the balance of the momentum, as shown in Fig.6(2), Fig.6(3). Once it grows to enough scale and strength, it will dominate the flow field nearby. Similarly, it cuts off the vorticity transportation to the developed vortex with negative vorticity, and leads the developed vortex shedding, as shown in Fig.6 (3). Above-mentioned courses take place alternately and a vortex street comes into being.

Fig. 7 shows the flow field at the second measurement location in relative coordinate system with velocity of $7 \mathrm{~m} / \mathrm{s}$ along $X$-axis. The vortices still have very strong entrainment capability after shedding and roll up the main flow into the wake until their breakdown, which will favor combustion by mixing enhancement.

\subsection{Analysis on the flow behind EBMC flameholder}

Fig. 8 shows the flow field at first location behind EBMC flameholder with the main flow velocity of $10 \mathrm{~m} / \mathrm{s}$ and jet velocity of $20 \mathrm{~m} / \mathrm{s}$. Under the experimental condition, its characteristic is roughly the same as that of the V-gutter flameholder, existing recirculation zone, vortex street, alternate formation and shedding of large scale vortices. But the details are different with those of the V-gutter flameholder.

By comparing Fig.8 with Fig.6, it can be observed that the vorticity in large-scale vortices behind EBMC flameholder is higher than that of V-gutter flameholder. It stems not only from the boundary layer of the flameholder, but also from the jet curtain. Two parts of vorticity are in the same sign and can merge and strengthen each other. In addition, the jet increases the size of the vortices that is obviously larger than the base width of the flameholder. All these indicate that the vortices have stronger entrainment capability and will enhance the interaction between the main flow and the wake then improve the combustion performance.

In Fig.8 (3), the phenomenon with two symmetrical large-scale vortices is illustrated. The instantaneous flow is not in the pattern of alternate formation and shedding of large-scale vortices. It was also observed in the experiments that, at the main flow velocity of $20 \mathrm{~m} / \mathrm{s}$ and jet velocity of $10 \mathrm{~m} / \mathrm{s}$ the wake flow always remains the pattern of vortex street similar to that of the V-gutter flameholder with no change taking place. While under the condition that both main flow velocity and jet velocity are equal to $10 \mathrm{~m} / \mathrm{s}$ or $20 \mathrm{~m} / \mathrm{s}$, symmetrical large-scale vortices appear at a lower frequency. The momentum ratio is proved to be an important parameter affecting the flow behind EBMC flameholder. 
It is suggested in this paper that two symmetrical vortices should be created by the jets at the nearly same time, and then grow up synchronously, which destroys the mechanism of alternate formation and shedding of vortices, weakens the vortex street, limits the size of the vortices and is harmful to combustion.

\subsection{Discussion on instantaneous viewpoint of the flame stability mechanism}

Above analysis reveals that turbulent heat and mass transfer in time-averaged recirculation zone is essencially by use of the entrainment of vortices. And there is profound effect of Formation, development and shedding of the vortices on the process of entrainment.

During developing process of the vortex, the main flow and the jet are entrained together and mixed with burned gas with high temperature, so the heat energy can be transferred to the fresh mixture. If the fresh mixture reaches igniting temperature and burns before large-scale vortex sheds, the combustion can remain steady. As the development of the vortex, fresh mixture is further entrained into and burns so that the large-scale vortex becomes a high temperature ignition source. Once a new vortex with opposite sign vorticity forms, the energy and radicals are transferred from the burning vortex to it, resulting in its burning and becoming a new ignition source. Accordingly, the source hands on with the alternate formation and shedding of vortices.

After large scale vortex sheds, due to its strong entrainment capability the fresh mixture is still entrained into continuously and burns around it, so that the whole wake flow and adjacent main flow all get into burning.

It can be concluded that the size, strength and shedding frequency of large-scale vortices have profound effect on combustion performance. The larger is the vortex scale and the more slowly does the vortex shed, the more enough time does fresh mixture have to be ignited and burn.

With the lean flame stability of the bluff body flameholder as example, combustion phenomena will be explained by above viewpoint as follows.

As the decrease of the equivalence ratio of the main flow, chemical reaction rate of unburned mixture decreases and heat release reduces in unit time or unit volume. When the energy is not much enough to ignite the fresh mixture entrained by the large-scale vortex, flame lean quenching happens.

It was well known that the shedding frequency of large-scale vortices increases with the main flow velocity. And their lifetime shortens correspondingly. When the lifetime reduces to a certain limit as the main flow velocity increasing, there is not enough time for the fresh mixture to be ignited and the flame quenches. The equivalence ratio will have to be raised to increase the reaction heat release in unit time or unit volume so as to shorten the igniting delay time of fresh mixture. Therefore, lean stability limits become narrower as the increase of the main flow velocity.

As the increase of base width of the flameholder, the size of the vortices becomes larger and the shedding frequency decreases. The fresh mixture has enough long time to be ignited, which improves the combustion stability.

From above, lean flame stability can be explained very well by the instantaneous viewpoint of the flame stability mechanism. But its rationality needs to be verified further. 
For EBMC flameholder, the jet from trailing edge increases the size of the vortices that is obviously larger than the base width of the flameholder. The higher is the momentum ratio of the jet to the main flow, the larger is the vortex size and the more slowly should the vortices shed, which can improve the combustion performance. But when the momentum ratio is too high, the vortex street is destroyed and the phenomena with two symmetrical vortices appear, which limits the size of the vortices and is harmful to combustion. Therefore, there exists an optimal momentum ratio of the jet to the main flow.

\section{Conclusions}

The detailed near-wake flow behind the Edge Blowing Mixture Curtain flameholder and the V-gutter flameholder was measured by using 2D cross-correlation on-line PIV in a low speed wind tunnel. Some conclusions can be drawn from the experiments:

There is an evolution process of alternate formation, development and shedding of large scale vortices which is called as vortex street in the near wake of both EBMC flameholder and the V-gutter flameholder. However, the jet from trailing edge increases the size of the vortices.

When the momentum ratio of the jet to the main flow is high, symmetrical large-scale vortices appear which weakens the vortex street and is harmful to combustion. But the phenomena don't take place when the momentum ratio of the jet to the main flow is low. The momentum of the jet to the main flow is a primary dynamic parameter affecting the flow behind EBMC flameholder.

Based on analysis about the near-wake flow, the instantaneous viewpoint of the flame stability mechanism was brought forward in this paper. Formation and shedding of vortex in near-wake flow govern the combustion process. If the fresh mixture entrained reaches igniting temperature and burns before large-scale vortex sheds, the combustion can remain steady. Large-scale vortex provides essential condition for flame spreading as ignition source. Then the heat release and radicals are transferred to next vortex, which will become a new ignition source with its development. So the source hands on with the alternate formation and shedding of vortices. The larger is the dimension of vortices and the more stable are the vortices, the better is the flame stability. The viewpoint needs to be verified further. 


\section{Reference}

[1] K.Sridhara, M.S.Chidananda, P.A.Paranjpe., "Jet curtain flameholder for aircraft afterburners", ASME 78-GT-95.

[2] K.Sridhara, M.S.Chidananda, "Fresh mixture entrainment in a jet curtain flameholder", Fifth International Symposium on Airbreathing Engines, Bangalore, India, February 16-21 (1981).

[3] T.Tamaru, K.Shimodaira, "Investigation of hydrogen-fueled turbo-ramjet engine combustors with jet stabilized flames", ISABE 95-7066.

[4] Gao Ge, Ning Huang, "Combustor gas dynamics", Press of Sciences, 2st Edition, (1987).

[5] Yang Maolin, Quan Zhong, "Experimental investigation on EBMC flameholder", Journal of Aerospace Power, Vol.13, No.2, Apr., (1998).

[6] C.N.Raffoul, A.S.Nejad, R.D.Gould, S.A.Spring, "An experimental and numerical study of the isothermal flowfield behind a bluff body flameholder", Transactions of the ASME, Journal of Engineering for Gas Turbines and Power, Vol.119, APRIL, (1997), pp328-339.

[7] D.R.Ballal, T.H.Chen, W.J.Schmoll, "Fluid Dynamics of a Conical Flame Stabilizer", Transactions of the ASME, Journal of Engineering for Gas Turbines and Power, Vol.111, Jan. , (1989), pp97-102.

[8] Jeong J, Hussain F, "On the identification of a vortex", J. Fluid Mech, (1995), 285, pp69 94.

[9] Baojie Liu, Guanghua Wang, Ge Gao, "A PIV study of near wake flow of airfoil, Part II - dynamic mechanism", Journal of Aerospace Power, (1999), Vol.14, No.2, pp125-130. 


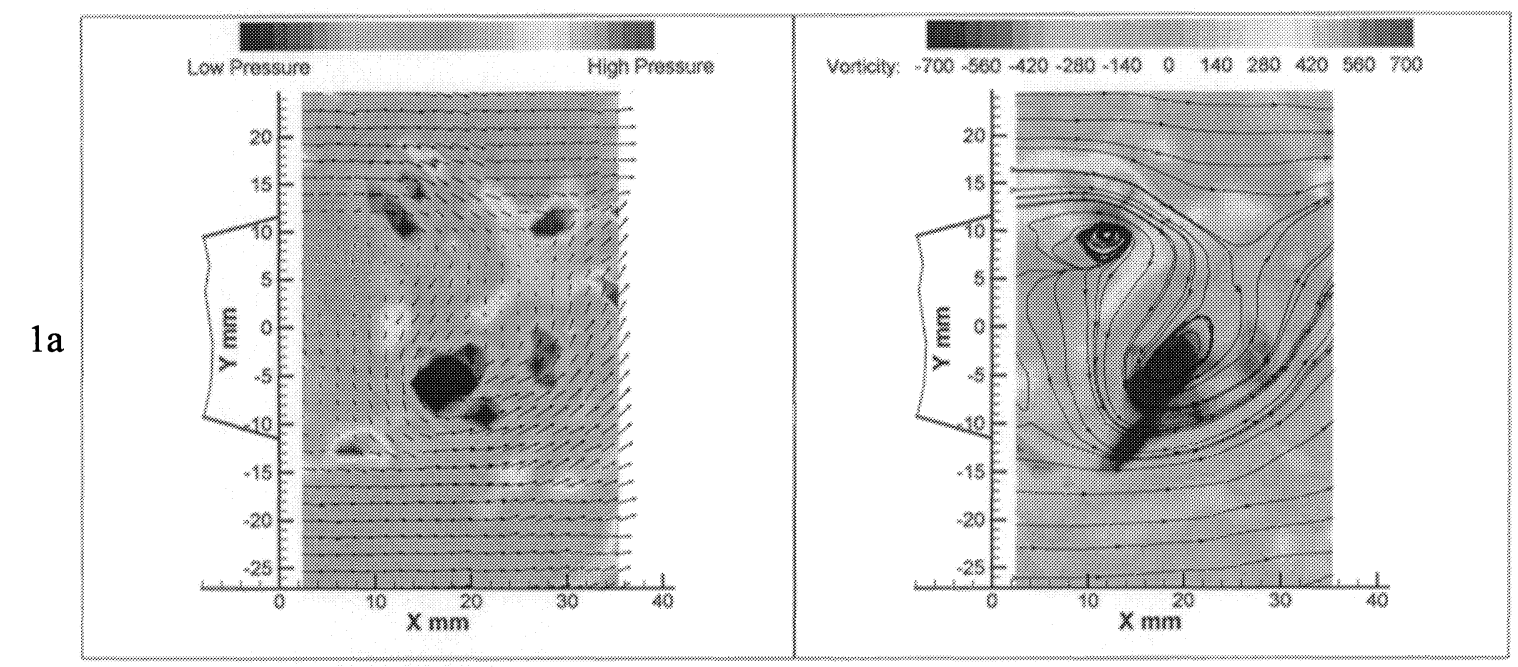

$1 b$
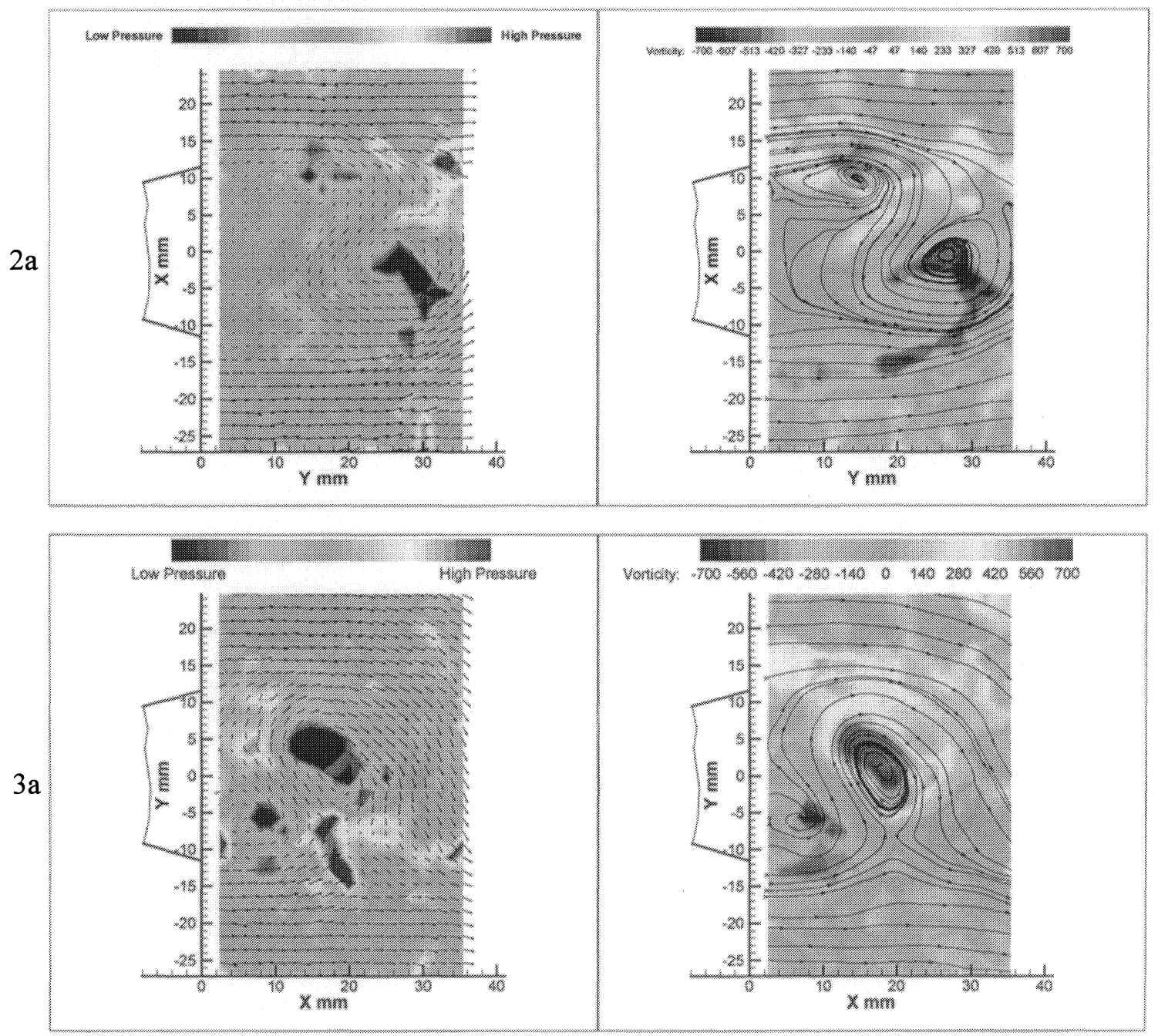

Fig.6 Instantaneous flow at first location behind V-gutter flameholder $V_{m}=10 \mathrm{~m} / \mathrm{s}$ 


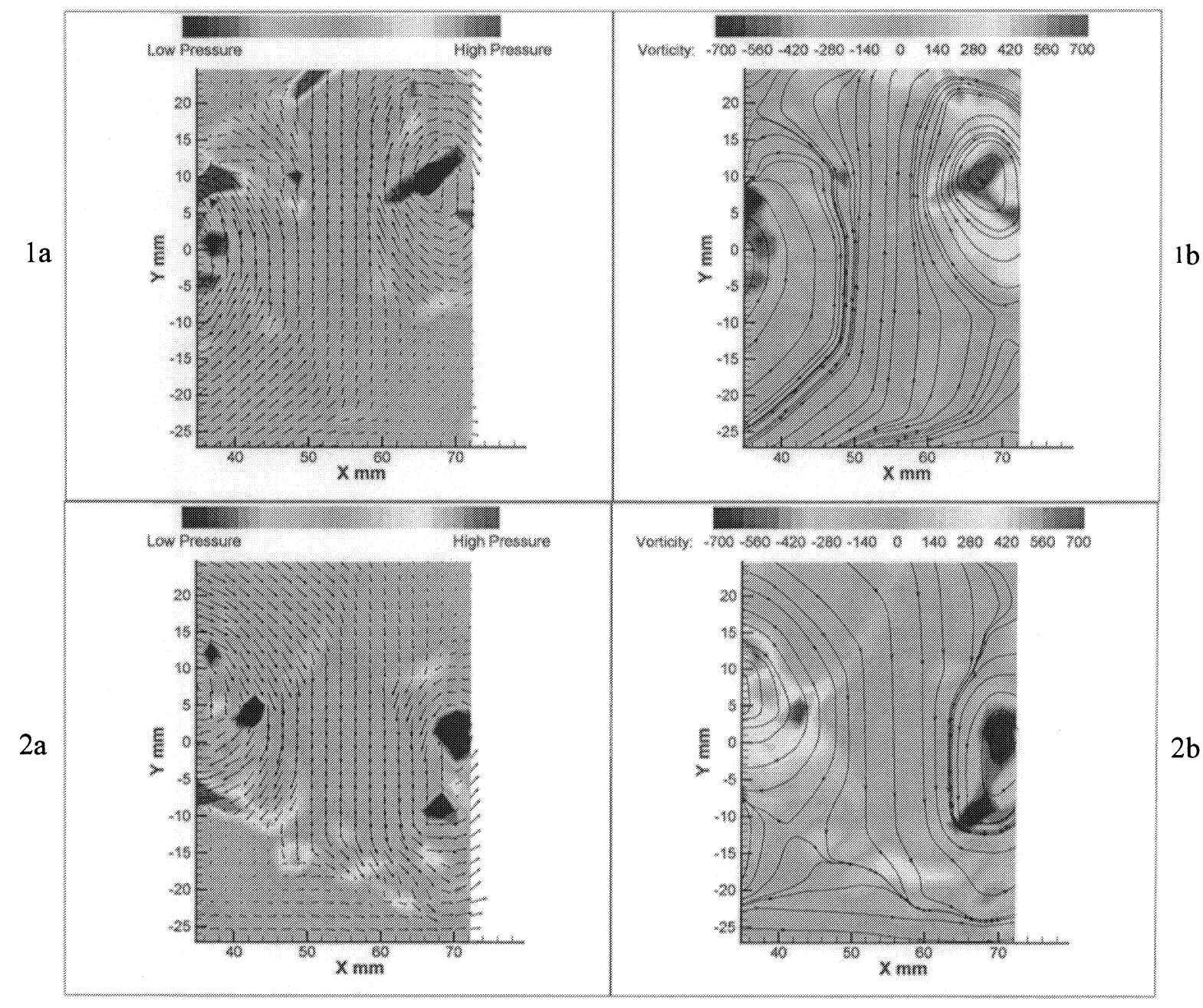

Fig.7 Instantaneous flow at second location behind V-gutter flameholder $V_{m}=10 \mathrm{~m} / \mathrm{s}$ in relative coordinate system with velocity of $7 \mathrm{~m} / \mathrm{s}$ along $X$-axis 


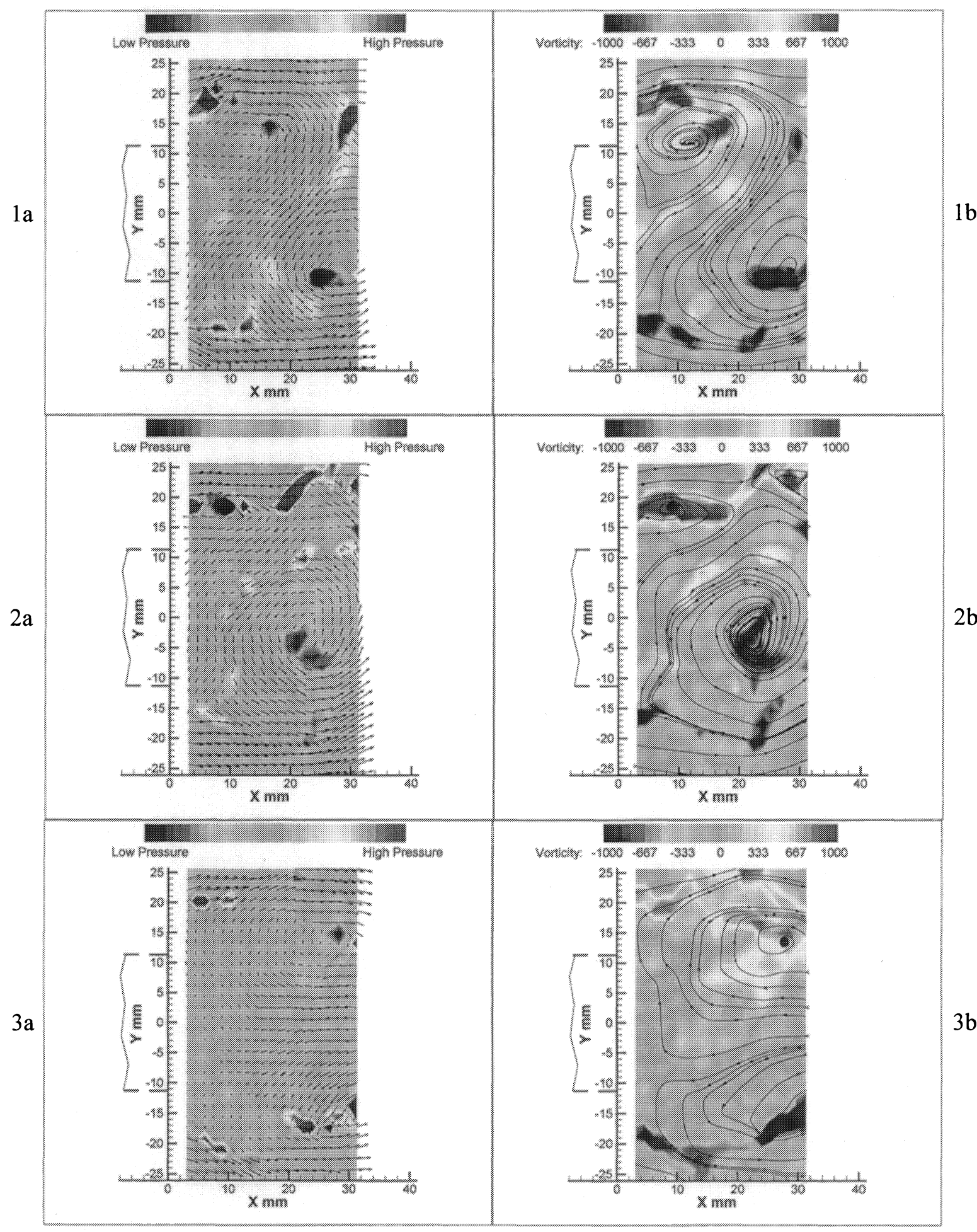

Fig.8 Instantaneous flow at first location behind EBMC flameholder $V_{m}=10 \mathrm{~m} / \mathrm{s} V_{j}=20 \mathrm{~m} / \mathrm{s}$ 